\title{
Comment
}

\section{to: Borch-Johnsen K, Colagiuri S, Balkau B et al (2004) Creating a pandemic of prediabetes: the proposed new diagnostic criteria for impaired fasting glycaemia. Diabetologia 47:1396-1402}

Received: 20 December 2004 / Accepted: 15 January 2005 / Published online: 4 March 2005

(C) Springer-Verlag 2005

To the Editor: The DETECT-2 group [1] recently described the pandemic of prevalent pre-diabetes that will occur with adoption of the new American Diabetes Association (ADA) criteria for IFG [2], leading to a more than threefold increase in prevalence. The aim of this note is to determine if this newly identified IFG group has a rate of incident diabetes that would support such a change, following on from a report in Singapore [3].

We determined incident diabetes rates in subjects with IFG according to the previous fasting glucose criteria (6.1-6.9 $\mathrm{mmol} / \mathrm{l})$ and according to the new additional criteria (5.6-6.0 mmol/l) among 2176 men and 2276 women aged 30 to 64 years in the French D.E.S.I.R. cohort (data from an epidemiological study on the insulin resistance syndrome), who were followed up for up to 6 years (mean age 47 years at baseline). Diabetes was defined at baseline and at follow-up by fasting plasma glucose of $7.0 \mathrm{mmol} / \mathrm{l}$ or

B. Balkau $(\bowtie) \cdot$ T. Hillier $\cdot$ E. Vierron

INSERM U258-IFR69,

16 Avenue Paul Vaillant-Couturier,

94807 Villejuif cedex, France

e-mail: balkau@vjf.inserm.fr

Tel.: +33-1-45595161

Fax: +33-1-47269454

\section{T. Hillier}

Center for Health Research Northwest/Hawaii,

Kaiser Permanente,

Portland, OR, USA

\section{A. D'Hour}

Institut Inter-Régional pour la Santé,

Le Mans, France

P. Lépinay

Centre d'Examens de Santé,

Orléans, France

B. Royer · C. Born

Institut Inter-Régional pour la Santé,

La Riche, France higher, or treatment with an oral hypoglycaemic agent, as recommended by the ADA. After 6 years of follow-up, 132 subjects developed diabetes (93 men and 39 women).

With the new definition, the prevalence of IFG at baseline in our cohort would increase from 13 to $40 \%$ in the men, and from 4 to $16 \%$ in the women (Table 1). While there would be a three to four-fold increase in the prevalence of IFG, the incidence rate of diabetes in the new IFG group would be less than one seventh of that of the original IFG group, bringing into doubt its usefulness as a diabetes risk group. These significantly different incidence rates are even greater in our population than those from Singapore, where the new IFG group had between one third and one half the diabetes incidence of the original IFG group (diabetes was defined in this study on both fasting and 2-h glucose criteria after an 8-year follow-up) [3].

This Singapore study was not analysed by sex, and the comparison of IFG between men and women is of interest. In our study, the distribution by sex according to fasting glucose concentrations is very different, with only $60 \%$ of men having a normal glucose concentration $(<5.6 \mathrm{mmol} / \mathrm{l})$ in contrast to $84 \%$ of the women. Therefore it is not surprising that men had a significantly higher overall incidence rate: 7.8 vs 3.1 per 1,000 person-years of follow-up. However, this higher incidence is due to a very low conversion rate in normoglycaemic women, again two and a half times lower than men (Table 1, two-sided $p=0.044$ ). In contrast, for either of the IFG groups, the conversion rates were not significantly different between men and women. Normoglycaemic women appear to be protected from progression to diabetes in comparison to the men.

Sex differences in the prevalence of diabetes was noted over 25 years ago in the Rancho-Bernardo Study, when a higher prevalence of diabetes in men was identified on the basis of treatment and fasting hyperglycaemia alone [4]. This paper commented on other US studies that also showed a higher prevalence in men. Other studies in France have given the male : female ratio as 1.04 for treated diabetes [5] and 1.6 for diabetes screened on one fasting sample [6]. The DECODE study has shown that when stratified by age 
Table 1 Six-year incidence of diabetes $(95 \% \mathrm{CI})$, per 1,000 person-years of follow-up, according to strata of fasting glycaemia, age and sex. The D.E.S.I.R. Study

\begin{tabular}{|c|c|c|c|c|c|c|c|c|c|}
\hline & & \multirow{3}{*}{$\begin{array}{l}\text { Fasting } \\
\text { plasma } \\
\text { glucose }(\mathrm{mmol} / \mathrm{l})\end{array}$} & \multirow{3}{*}{$\begin{array}{l}\text { Base line } \\
\text { prevalence (\%) }\end{array}$} & \multirow{3}{*}{$\begin{array}{l}\text { Number of } \\
\text { person-years } \\
\text { of follow-up }\end{array}$} & \multirow{3}{*}{$\begin{array}{l}\text { Number of } \\
\text { new diabetic } \\
\text { patients }\end{array}$} & \multicolumn{4}{|c|}{ Incidence of diabetes per 1,000 person-years } \\
\hline & & & & & & \multicolumn{3}{|c|}{ Age (years) } & \multirow[t]{2}{*}{ Total } \\
\hline & & & & & & $30-44$ & $45-54$ & $55-64$ & \\
\hline \multicolumn{10}{|l|}{ Men } \\
\hline & & & & & & $n=971$ & $n=591$ & $n=614$ & $n=2176$ \\
\hline \multicolumn{2}{|c|}{ Normal glucose } & $<5.6$ & 60 & 7215 & 13 & 2.3 & 1.7 & 1.1 & $1.8(0.9-3.1)$ \\
\hline \multirow{2}{*}{\multicolumn{2}{|c|}{$\begin{array}{l}\text { Total } \\
\text { Women }\end{array}$}} & & 100 & 11943 & 93 & 4.9 & 8.5 & 11.5 & $7.8(6.3-9.5)$ \\
\hline & & & & & & & & & \\
\hline & & & & & & $n=973$ & $n=650$ & $n=644$ & $n=2267$ \\
\hline \multicolumn{2}{|c|}{ Normal glucose } & $<5.6$ & 84 & 10728 & 8 & 0.4 & 1.4 & 0.7 & $0.7(0.3-1.5)$ \\
\hline IFG & New & $5.6-6.0$ & 12 & 1440 & 9 & 5.5 & 7.0 & 5.9 & $6.2(2.9-11.9)$ \\
\hline
\end{tabular}

class, men generally had a higher fasting glucose concentration, women a higher post-challenge glucose concentration [7].

For incident diabetes, sex differences have also been seen in Mauritius in a cohort followed from 1987 to 1992, but not in a second cohort followed from 1992 to 1998 [8]. Diabetes was based on both fasting and 2-h glucose concentrations. Isolated fasting hyperglycaemia appears to be a predominant feature in men, isolated 2-h hyperglycaemia in women. Thus, our results, combined with data from other studies, highlight the importance of sex differences with IFG.

In summary, our results suggest caution against a quick adoption of the new IFG criteria, as the newly defined IFG group appears to have a much lower incidence of diabetes than the previously defined IFG group.

Acknowledgements T. Hillier is supported by an American Diabetes Association-European Association for the Study of Diabetes Trans-Atlantic Fellowship.

\section{References}

1. Borch-Johnsen K, Colagiuri S, Balkau B et al (2004) Creating a pandemic of prediabetes: the proposed new diagnostic criteria for impaired fasting glycaemia. Diabetologia 47:1396-1402
2. Genuth S, Alberti KG, Bennett P et al (2003) Expert committee on the diagnosis and classification of diabetes mellitus. Followup report on the diagnosis of diabetes mellitus. Diabetes Care 26:3160-3167

3. Tai ES, Goh SY, Lee JJ et al (2004) Lowering the criterion for impaired fasting glucose: impact on disease prevalence and associated risk of diabetes and ischemic heart disease. Diabetes Care 27:1728-1734

4. Barrett-Connor E (1980) The prevalence of diabetes mellitus in an adult community as determined by history or fasting hyperglycaemia. Am J Epidemiol 111:705-712

5. Ricordeau P, Weill A, Vallier N, Bourrel R, Fender P, Allemand H (2000) L'épidemiologie du diabète en France metropolitaine. Diabetes Metab 26 (Suppl 6):11-24

6. Gourdy P, Ruidavets JB, Ferrieres J et al (2001) Prevalence of type 2 diabetes and impaired fasting glucose in the middle-aged population of three French regions - the MONICA study 1995 97. Diabetes Metab 27:347-358

7. DECODE Study Group (2003) Age- and sex-specific prevalences of diabetes and impaired glucose regulation in 13 European cohorts. Diabetes Care 26:61-69

8. Soderberg S, Zimmet P, Tuomilehto J et al (2004) High incidence of type 2 diabetes and increasing conversion rates from impaired fasting glucose and impaired glucose tolerance to diabetes in Mauritius. J Intern Med 256:37-47 